\title{
Educational Goals Based on Key Competencies -Taking Mathematics Knowledge as an Example
}

\author{
Guanqun Ma: School of Mathematical Sciences, University of Jinan, Jinan, Shandong 250022, P R China. \\ :Sun Shurong: School of Mathematical Sciences, University of Jinan, Jinan, Shandong 250022, P R China. \\ Zhenlai Han: School of Mathematical Sciences, University of Jinan, Jinan, Shandong 250022, P R China.
}

\begin{abstract}
Key competencies have become a hot topic in the current education circle. The concept of key competencies requires cultivating people with all-round development, which is the further deepening of quality education. So, what is the connection between the key competencies and education? The educational goal under the key competencies concept should be divided into three layers: first, the concept of knowledge, from knowledge understanding to knowledge transfer to knowledge innovation, second, problem solving, problem solving is the process of knowledge internalization, third, subject thinking layer, Disciplinary thinking is the highest level of cultivating student literacy. Link the three together, grasp the direction of educating people as a whole, and train people in all aspects.
\end{abstract}

Key words: Key competencies, Educational goals, Knowledge view, Problem solving, Subject thinking.

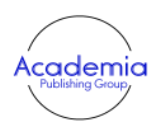

International Journal of Educational Studies Vol. 1, No. 1, pp. 12-15

2018

DOI: $10.53935 / 2641-533 x$. 1 lil 16

Corresponding Author: Shurong Sun Email: sshrong@163.com

Funding: This study received no specific financial support.

Acknowledgment: This paper is the stage achievement of Jinan University Graduate Education Innovation Project "Research on Evaluation Criteria and System of Graduate Education Quality for Professional Degrees in Shandong Province under the Backrees in "Dhandong Province under the Background of "Double-first-class"Construction" (No. JDY1601) and "Research on Construction and Implementation of Quality Guarantee System for Graduate Education of Master of Education (No. JDY1707).

Article History:

Received: 26 September 2018

Revised: 19 October 2018

Accepted: 14 November 2018

Published: 7 December 2018

(C) 2018 by the authors; licensee Academic Publishing Group

\section{Introduction}

In 2014, the Ministry of Education issued the "Opinions on Comprehensively Deepening the Curriculum Reform and Implementing the Fundamental Tasks of Lide Shuren", and the Ministry of Education proposed a key competencies system. key competencies refers to the essential character and key abilities that students should have to meet the needs of lifelong development and social development. The understanding of key competencies is about the understanding of the core, and the discussion of key competencies is a hot issue in the current education. What does core literacy mean? How is the core understood? The proposal of the key competencies system is not a separate voice in China, but a world trend. At the beginning of this century, the Organization for Economic Co-operation and Development (OECD) took the lead in proposing a "key competencies" structural model. The problem to be solved is: What are the core knowledge, abilities and emotional attitudes that students in the 21 st century should possess in order to successfully integrate into the future society, in order to meet the needs of individual self-realization while promoting social development (Shi Jiu-ming 2014). The eight key competencies proposed by the EU include: use of mother tongue communication, use of foreign language communication, mathematical literacy and basic subject technical literacy (Dejan Hozjan 2009).

Key competencies is the embodiment of quality education. After years of education reform in China, quality education has achieved remarkable results, and students still need to improve and improve their sense of social responsibility, innovation and practical ability. On September 10, 2018, the National Education Conference was held in Beijing. For the role and status of education, General Secretary Xi Jinping clearly stated in his important speech that "education is the country's plan, the party's plan" and the first time 


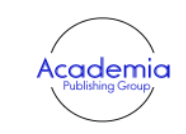

International Journal of Educational Studies Vol. 1, No. 1, pp. 12-15

2018

DOI: 10.53935/2641-533x.v1i1.16

Corresponding Author: Shurong Sun Email:sshrong@163.com

Funding: This study received no specific

financial support.

Acknowledgment: This paper is the stage achievement of Jinan University Graduate Education Innovation Project "Research on Evaluation Criteria and System of Graduate Education Quality for Professional Degrees in Education Quality for Professional Degrees in Shandong Province under the Background of "Double-first-class"Construction" (No. JDY1601) and "Research on Construction and Implementation of Quality Guarantee System for Graduate Education of Master of Education " (No. JDY1707)

Article History:

Received: 26 September 2018

Revised: 19 October 2018

Accepted: 14 November 2018

Published: 7 December 2018

(C) 2018 by the authors; licensee Academic

Publishing Group "education" It is an important cornerstone of national rejuvenation and social progress. It is a modern political project that benefits the future (Zhou Hongyu et al 2018). The key competencies is the collection of knowledge, skills, problem solving, and disciplinary thinking.

\section{Mainstream Perspectives on Educational Goals}

The educational goal is the degree and direction of the education of the educators. The education is mainly to teach and educate people. In 1952, the Ministry of Education first defined the basic concept of "double base", namely basic knowledge and basic skills. Education aims to cultivate students' knowledge. In 2001, the Ministry of Education first appeared in the "Basic Education Curriculum Reform Program (Trial)" the idea of "three dimensions of knowledge and skills, processes and methods, emotional attitudes and values". Although the educational reform of the three-dimensional goal has made great progress, there are some problems. In traditional education, the main focus is on the understanding of knowledge, which is the first level of knowledge and skill modules in the three-dimensional goal. In the teaching, there are obviously many shortcomings in the training of the second and third modules. In 2014, the key competencies was proposed to cultivate people in all aspects and make up for the shortcomings of the three-dimensional goal. The key competencies requires the integration of knowledge. It is the embodiment of quality education and cultivates the key literacy of students.

Education is mainly about teaching and educating people. The process of education is not only to cultivate students' understanding of knowledge, but more importantly, to internalize through knowledge learning and become a person with thoughts and thoughts. The connotation of Li Yi's key competencies in the "key competencies " is divided into three levels: the bottom-level "double-base pointing", with the basic knowledge and basic skills as the core; The middle layer is the "problem solving direction", which is mainly based on the basic method obtained by solving the problem; the top-level "scientific thinking direction" refers to the process of understanding and internalizing in the process of systematic learning, gradually forming a relatively stable thinking ability and problem-solving thinking methods and values, preliminary Get a world view and methodology to understand the world and transform the world (Li Yi and Zhong Bochang 2015).

\section{Teaching Objectives Based On Key Competencies}

Under the key competencies concept, the educational objectives are mainly divided into three layers. One is the double-basic level, which is mainly the understanding of the concept of knowledge, and the other is the problem-solving layer. For the ability to train students to solve problems, the third is the disciplinary thinking layer. Student's disciplinary thinking. From these three levels, we will develop students' key abilities and essential qualities to meet individual and social needs and achieve real educational goals. So how do you truly integrate core literacy into teaching? It is necessary to stand on the level of subject thinking to carry out teaching practice and to engage in rational dialogue and reflective teaching with students. At the level of disciplinary thinking, through the solution of problems, the students' worldview and methodology are cultivated subtly, and at the same time, students are awakened to reflect on the methods used in the process of knowledge internalization.

\subsection{Knowledge of Knowledge}

The concept of knowledge refers to the understanding and perception of knowledge learning. With the reform of education, the status of knowledge has gradually been weakened from the double base to the threedimensional goal. Socrates said that virtue is knowledge, knowledge is the foundation of literacy, and knowledge is the source of core literacy. The stability of the concept of knowledge directly affects the cultivation of the problem-solving layer and the disciplinary thinking layer. Under the guidance of the key competencies concept, the teaching objectives should be formulated from the perspective of knowledge, and the key abilities and essential characters that students should possess should be cultivated. For the concept of knowledge, it is mainly from the three dimensions of understanding, migration and innovation to analyze how to cultivate the key abilities that students should possess.

\subsubsection{Understanding of Knowledge}

The understanding of knowledge is the understanding of the nature of knowledge. Only deep understanding can find out the origin of things. The understanding of knowledge is the same. In-depth 
understanding of knowledge can understand the essence of knowledge, integrate and accumulate knowledge, and apply knowledge flexibly. To achieve the process of internalization, basic knowledge is the basis for problem solving and cultivating thinking. The accumulation of knowledge is the cornerstone for cultivating students' all-round development. As far as mathematics is concerned, the understanding of knowledge is that students deeply understand the basic concept theorems and properties, and clarify the connection between various knowledge points. Symbolize abstract mathematical concepts to solve mathematical problems. Take the high school mathematics arithmetic series as an example for analysis.

Case 1: When learning the equivalence sequence summation formula $S \_n=n\left(a \_1+a \_n\right) / 2$, the student must grasp what is the arithmetic progression, and only after real understanding of what is waiting for the knowledge of the sequence, can the Learn, accept and master the derivation of the summation formula.

\subsubsection{Migration of Knowledge}

Knowledge transfer is the effect of learning on another type of learning. The continuous process of learning is based on the knowledge, cognitive and motor skills and learned attitudes that learners already have ${ }^{[4]}$. Knowledge transfer is to solve the problem by migrating its existing knowledge base to another situation through the learning and accumulation of knowledge in the past. In this learning process, the way in which new problems can be solved based on existing knowledge and cognitive structure is called the migration of knowledge. Take the knowledge of conic curve in mathematics as an example for analysis. When learning the standard equations and properties of hyperbola, if the knowledge of the ellipse is transferred and the connection between the two is established, it is more conducive to the study of knowledge, not only learning new knowledge, but also consolidating the old knowledge. Metacognition ability is cultivated.

\subsubsection{Innovation of Knowledge}

The innovation of knowledge refers to further thinking, changing thinking, and reminiscent of new problems based on existing problems. For example, based on Case 2, students can move from elliptical problems to hyperbolic or parabolic problems, and this is a process of knowledge innovation. The development of open questions is also a way to cultivate students' innovative thinking. Through the accumulation of knowledge to solve abstract problems, deep thinking, form their own mode of thinking, improve the ability to find problems, solve problems, and be able to make inferences. This is to cultivate students' innovative thinking, and then to facilitate the formation of literacy. The key competencies concept requires students to achieve comprehensive development of knowledge and skills and thinking.

By analyzing the three dimensions of the concept of knowledge, we will cultivate students' knowledge, skills and thinking, and determine the direction of the curriculum goals.

\subsection{Problem Solving}

Problem solving is the integration of all knowledge and skills. It refers to the process of solving problems through knowledge of existing, using certain methods and methods, and thinking operations in certain situations. Through the study and accumulation of knowledge, the problem is solved and the thinking mode is formed. This is a process of internalization of knowledge. Through the solution of problems, the knowledge and skills are integrated, and their own thinking patterns are formed to cultivate students' cautious, singleminded attitude and the spirit of scientific research. For example, in the process of solving problems in mathematics, students can solve problems by themselves. When they encounter difficulties, they can solve problems through various discussions between classmates or consulting teachers. In the process of solving problems, we can cultivate the ability of independence and self-cultivation, and also cultivate students' spirit of cooperative inquiry and creativity. The solution of the problem is the process of internalization of knowledge and the basis for cultivating students' thinking.

\subsection{Subject Thinking}

The last layer of the teaching goal under the key competencies concept is the cultivation of thinking. Only by internalizing knowledge can we cultivate the thinking and form the literacy. The subject thinking is mainly to examine the world view and methodology hidden behind the students' specific problems, in order to awaken students to reflect and evaluate the problem solving methods. If knowledge and problem solving are the basis 
for cultivating students' key abilities and essential characters, then, the height of thinking is the height that determines the formation of literacy.

The cultivation of thinking is undoubtedly the cultivation of a person's world view and methodology. Knowledge is the origin of thinking. Problem solving is the basis of thinking. Only when knowledge is accumulated, can we think and solve problems, and the solution to them is methodology. Through the internalization of knowledge, the solution of problems, and the formation of one's own ideas, it is the formation of a worldview. Therefore, the cultivation of disciplinary thinking should be attributed to the accumulation of knowledge and the solution of problems. Disciplinary thinking is inseparable from both. Undoubtedly, only the connection between the students' knowledge, problem solving, and subject thinking can make the students develop as a whole.

\section{Conclusion}

The cultivation of teaching objectives based on key competencies is mainly analyzed from the three dimensions of knowledge view, problem solving and subject thinking. Knowledge is the source of all things. Problem solving is the process of internalizing knowledge. Disciplinary thinking is the process of thinking training on the basis of the former two. It is the highest level and is the key to realizing students' adaptation to individual and social lifelong development. The key to ability and essential character. However, the three are inextricably linked. Therefore, teachers should seek wisdom from upstream knowledge, which can take the direction of education as a whole, and cultivate students' development in all aspects. At the moment of education reform, it is imperative to integrate the key competencies concept into the construction and implementation of educational goals. However, the implementation of key competencies measures need to be improved step by step, not to build a feasible indicator can be fully executed, so more suitable indicators need us to continue to explore.

\section{References}

Shi Jiu-ming. (2014). Core literacy: In order to cultivate "all-round development". People's Education, 10: 13-15.

Dejan Hozjan. (2009). Key competences for the development of lifelong learning in the European in the european union .European Journal of Vocational Training, 1.

Zhou Hongyu, Cheng Guangxu, Song Naiqing, Wang Xiaojie, Sun Miantao, Kang Cuiping, Chen Peng, Long Baoxin, \& Zhai Zhanyong. (2018). Studying and Implementing the Spirit of the National Education Conference to Accelerate the Modernization of Education.Journal of Shaanxi Normal University(Philosophy and Social Sciences Edition), 47(06): 5-28.

Li Yi, \& Zhong Bochang. (2015). On "Core Literacy". Educational Research, 36(09): 17-23.

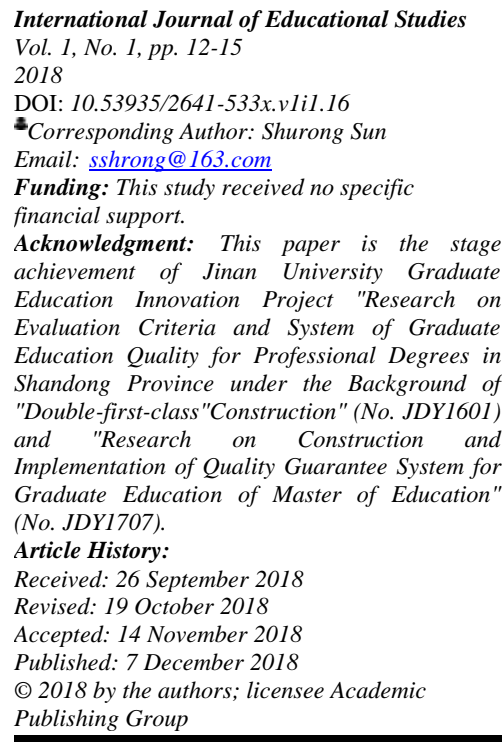

